\title{
Dam Breach Parameters and its Effects on Propagation of Flood Wave in the Downstream
}

\author{
[Patra K.C, Ritusnata Mishra]
}

\begin{abstract}
- our society gets huge benefits from the water storage dams, but the consequences are devastating if a dam fails. It causes extensive damage to the life and properties mostly due to short warning time. Important factors governing failure studies are the breach parameters that help to quantify the risk associated with dam break floods. Many empirical equations have been developed for predicting the breaching parameters associated with peak outflow and these equations are generally developed by regression analysis from the record of dam failure data. In the present work, a hypothetical failure of dam is modelled using MIKE 11. The required inputs in terms of PMF, river cross sections, area-elevation-capacity curves, Stage-Discharge data and dam specifications are provided for modelling. Towards this, data from Sarabgarh dam project in Orissa is used to model the breach parameters and propagation of flood waves in the downstream reaches using Mike 11 and other software. The flood hydrograph at different stations are analyzed to estimate the risk of overtopping of river bank and flooding. Besides a sensitivity analysis for various parameters that affects the maximum discharge and maximum water level has been carried out successfully.
\end{abstract}

Keywords - Dam safety, Mike 11, Breach parameters, Flood hydrograph, Flood wave

\section{Introduction}

Dams provide many benefits to our society, but floods resulting from the failure of constructed dams have also produced some of the most devastating disasters over last two centuries. When dams fail, property damage is certain, but loss of life can vary drastically with the extent of the inundation area, the size of the population at risk, and the amount of warning time available. A dam break analysis can be sub divided into two tasks. First is the prediction of reservoir outflow hydrograph from a dam break event and second is routing of this hydrograph through the downstream to determine the downstream effects. Major causes of failures identified are overtopping due to inadequate spillway capacity $(34 \%)$, foundation defects $(30 \%)$, piping and seepage $(28 \%)$. By using a numerical modelling of dam failure a proper approximation of the amount of maximum discharge and water level in downstream area is assessable. Dam failure is an unstable Hydraulic Phenomena and the numerical simulation requires a strong mathematical modelling. Nowadays the different mathematical modeling tools such as the BREACH, MIKE11, DAMBRK, and SMPDBK are available for dam break simulation. In the present work a one dimensional hydrodynamic models have been used to obtain output flow hydrograph which is routed in lower reaches of the river to

Professor Kanhu Charan Patra

National Institute of Technology Rourkela -769008 India

Ritusnata Mishra

National Institute of Technology Rourkela-769008 India get the maximum velocity, water level and discharge during the propagation of flood waves at the downstream reaches. For one dimensional modeling of dam break output flow, MIKE11 hydrodynamic module is used. In this model, dam break development caused by overtopping with attention to damage is investigated using different approaches like energy equation and Saint-Venant equations by using the finite difference. The propagation and transformation of the generated waves has been modeled using DHI's MIKE 11 hydrodynamic module, which is based on the nonlinear shallow water equation

\section{Methodology}

In MIKE11, implicit method and Finite Difference are used to solve the fluid equations in an unsteady state based on conservation of mass and Saint-Venant momentum equations. Solution to the equations is 6 points Abbott scheme in which discharge and water level are calculated at the grid Points namely $H$ (height of water) and $Q$ (discharge). Most of the dambreak setups consist of a single or several channels, a reservoir, the dam structure and perhaps auxiliary dam structures such as spillways, bottom outlets etc. The River channel description is based on a cross section data. However, due to the highly unsteady nature of dambreak flood propagation, it is advisable that the river topography be described as accurately as possible through the use of as many cross-sections as necessary, particularly where the cross-sections are changing rapidly. The governing equations used for modelling through MIKE 11 HD (hydrodynamic) are continuity equation and mass conservation equations that together makes it to the SaintVenant equation.

\section{A. Reservoir Description}

In order to obtain an accurate description of the reservoir storage characteristics, the reservoir can be modelled as a single H-point in the model. This point also corresponds to the upstream boundary of the model where inflow hydrographs are specified. In this way the surface storage area of the dam is described as a function of the water level. At the Q-point, where the dambreak structure is located, the momentum equation is replaced by an equation which describes the flow through the structure which is sub critical or super critical. The spillway is described as a separate branch. Fig 1 illustrates typical setup for dam break simulation.

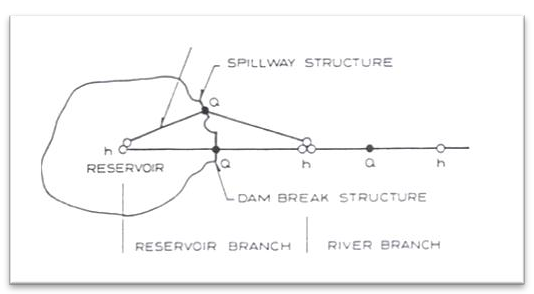

Fig 1 Setup for dam break modeling by MIKE11 
Proc. of Eighth International Conference On Advances in Civil, Structural and Mechanical Engineering - ACSM 2018 Copyright (C) Institute of Research Engineers and Doctors, USA. All rights reserved.

ISBN: 978-1-63248-154-2 doi: 10.15224/978-1-63248-154-2-08

\section{Study Area}

Sarabgarh irrigation project is a medium storage project built on a tribuitary of Mahanadi river basin in Odisha state. The dam (Fig 2) is built across river Ichha Nallah a tributary of the river Mahanadi, near village Sarabgarh in Odisha.

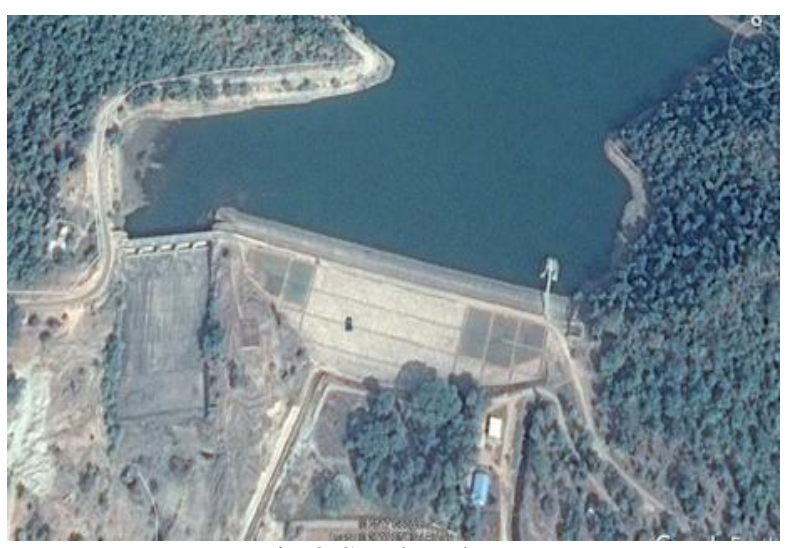

Fig 2 Sarabgarh Dam

\section{Modelling the Dam}

Hydrodynamic modelling of the river requires river network, cross-sections, hydrodynamic parameters and boundary conditions. A brief description of the numerical scheme, river network, boundary conditions, calibration and validation of the model is given below.

\section{A. River Network Scheme}

The stage and discharge of the Ichha river are influenced by the backwater curves and the effect is propagated up to the downstream of dam under normal flow condition, the crest level of the dam is higher than the maximum backwater level. MIKE 11 treats the domain as a series of cross-sections perpendicular to the flow direction.

\section{$B$. Boundary Conditions}

The hourly discharge hydrograph at Sarabgarh dam and the hourly time series of the levels during the flood have been considered as the upstream and downstream boundary conditions respectively, for the foregoing 1D hydrodynamic modelling.

\section{Hydrodynamic Parameters}

The dam break structure is defined at the $Q$ point. The momentum equation is not used at this location. Rather an equation which describes the flow through the structure is used. As the momentum equation is not used at the $Q$ point, the $\Delta x-$ step is of no relevance. The dam is modeled for the maximum $\Delta x$ for the river branch, where the dam is taken to be greater than the distance between two cross-sections in the reservoir branch so that no cross-section is interpolated between the actual cross-sections in the network editor. Here dam is defined as the starting chainage point. Different features of the dam are specified here. The failure moment is taken as reservoir Water Level and Failure Mode as time dependent. Breach calculation method is selected as energy based approach.

\section{v. Results}

The FRL of the reservoir is $307.50 \mathrm{~m}$ and therefore the initial water level of the reservoir is fixed at $307.50 \mathrm{~m}$ in the modeled dam. It signifies that the reservoir is at FRL when the PMF impounds the reservoir. The designed flood carrying capacity of the spillway is set as $695 \mathrm{~m}^{3} / \mathrm{s}$ whereas the PMF has a peak discharge of $885 \mathrm{~m}^{3} / \mathrm{s}$. The PMF starts at 0 hours with a peak of $885 \mathrm{~m}^{3} / \mathrm{s}$ at 18 hour which exceeds the design spillway capacity at 16 hours. It implies that spillway is inadequate to take this amount of discharge and as the result; the flood water overtops the dam. Breaching starts at the time of $16.93 \mathrm{hr}$. The initial level of the breach is $310.6 \mathrm{~m}$ and it continues till the $300.92 \mathrm{~m}$ which denotes that the dam was no longer capable of holding back water in the reservoir. The maximum outflow (Fig 3) from the breached dam was $7536 \mathrm{~m}^{3} / \mathrm{s}$. The time taken by the maximum discharge to reach the downstream is at $17.93 \mathrm{hr}$ which is $1 \mathrm{hr}$ from the breach initiation time. The dam failure results in flood wave making the downstream area flood prone.

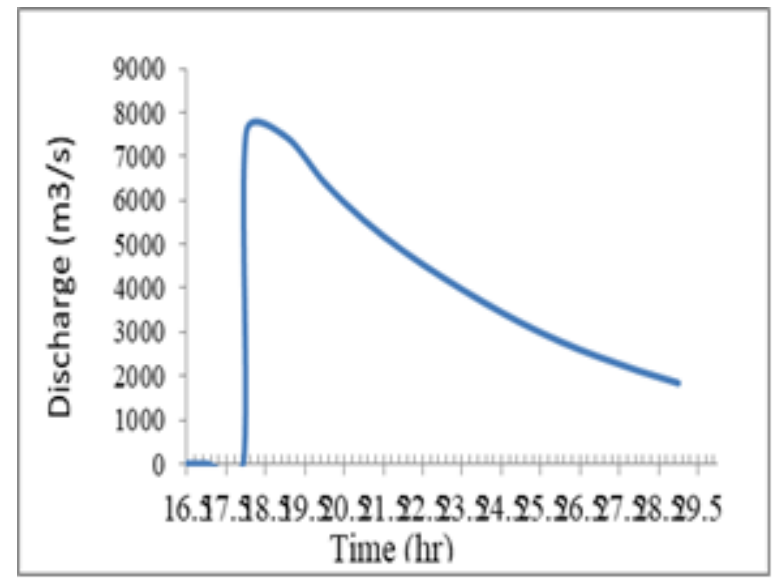

Fig 3 Flood Hydrograph from Breach

\section{A. Effect on the Downstream Region}

To analyze the impact of the flood wave resulting from the breached dam, 29 stations are selected in the downstream region. Out of these 29 stations 14 are most critical stations for the risk of flooding due to flood water overtopping of the bank. Station 29 which is located at a distance of $27.7 \mathrm{~km}$ from the zero chainage affects the downstream villages located at a distance of $100 \mathrm{~m}$ across the river bank. There may be a chance of huge flood at this location. Similarly Station 17 is located at a distance of 16 $\mathrm{km}$ from the zero chainage affects the downstream villages at a distance of $200 \mathrm{~m}$ from the river bank. These 2 regions seem to be the most critical for flooding. Except this, station numbers 28, 26, 22, 21 were also critical points which may affect the locality at the downstream side during flood.

The water level and discharge with respect to time of these critical stations are shown in the Fig 4(a) and in Fig 4(b) respectively. From these graphs, it can be concluded that station 17 (chainage $16 \mathrm{~km}$ ) is the most critical point in terms of highest water level and discharge. 
Proc. of Eighth International Conference On Advances in Civil, Structural and Mechanical Engineering - ACSM 2018 Copyright (C) Institute of Research Engineers and Doctors, USA. All rights reserved.

ISBN: 978-1-63248-154-2 doi: 10.15224/978-1-63248-154-2-08

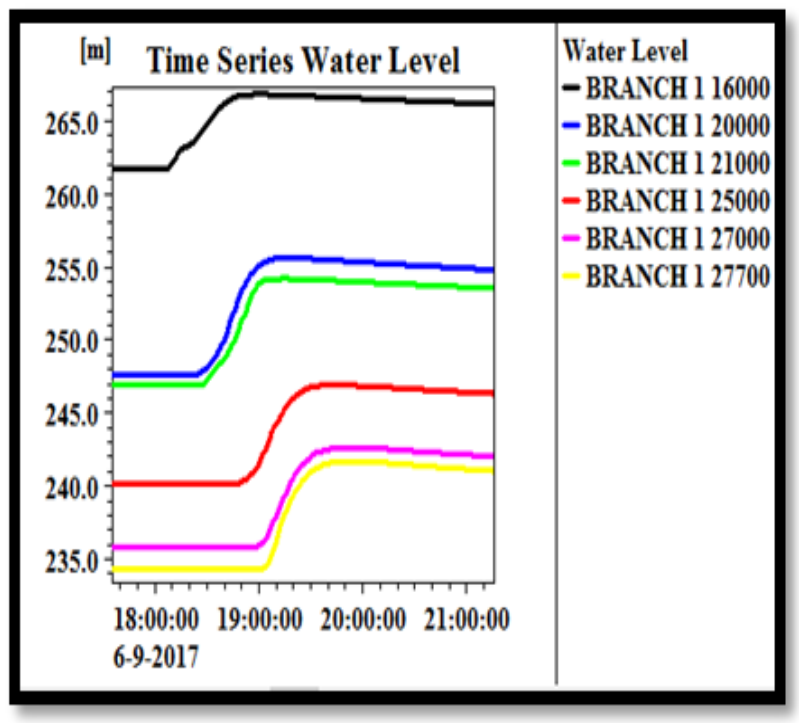

Fig 4(a) Water Level at Different Stations

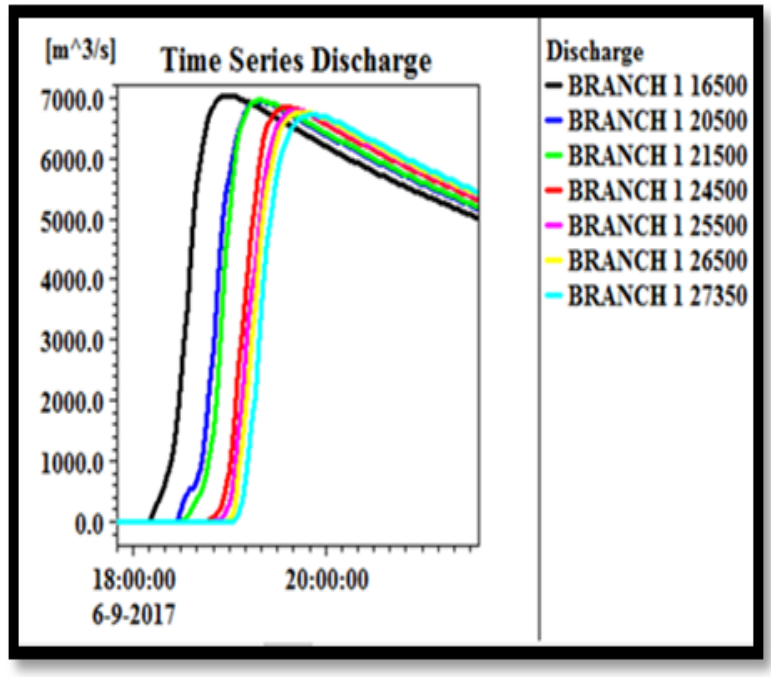

Fig 4(b) Discharge at Different Station

Fig.5 shows the longitudinal bed profile of river Ichha with minimum bank level, maximum water level reached due to dam break in the downstream of the dam site. As we analyze from the longitudinal profile and from the study of topography the area situated near the river Ichha that is between $3 \mathrm{Km}$ to $6 \mathrm{Km}$ will be highly flooded during the dam break.

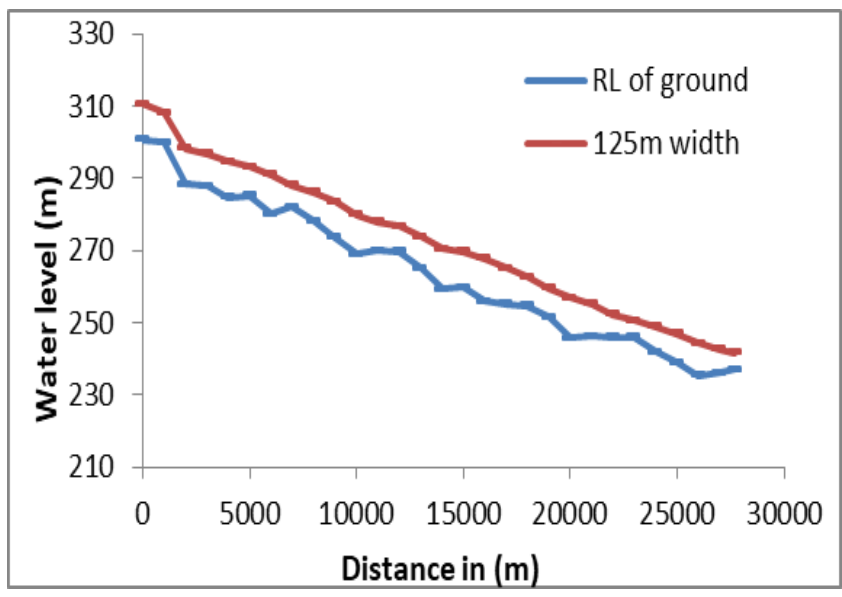

Fig.5: Longitudinal Bed Profile of River Ichha

\section{B. Sensitivity Analyses}

Flood hydrograph which is the output of the simulation is dependent on the input parameters. The maximum water level and peak discharges at different location are dependent on the breach input parameters during modelling. A small variation in the input parameters can alter the results significantly. Therefore, a sensitivity analysis of the maximum water level and peak discharge to different input breach parameter is carried out. The fore breach parameters selected for sensitivity analysis are given as:

1. Breach Time

2. Breach Width

3. Inflow as PMF(probable maximum flood)

4. Manning's roughness coefficient

Increasing the breach time means more time is required for complete development of the breach. With the increase in breach time, an outflow hydrograph with a large time base is obtained. A decrease in breach time means within a short duration the breach develops fully and dam fails. In the initial model, a breach time of $1 \mathrm{hrs}$, breach width of $125 \mathrm{~m}$ and design flood of $7536 \mathrm{~m}^{3} / \mathrm{s}$ is assumed for the purpose of analysis. For sensitivity analysis, in first case keeping other parameters constant the breach time is increased to $2 \mathrm{hr}$ and 3 $\mathrm{hr}$ which is twice and thrice the initial value respectively. It is observed that for an increase in breach time to $2 \mathrm{hr}$, the design flood was $7091 \mathrm{~m}^{3} / \mathrm{s}$, similarly for $3 \mathrm{hr}$ the design flood is $7298 \mathrm{~m}^{3} / \mathrm{s}$. The variation in peak discharge and breach initiation time is shown in Fig 6.

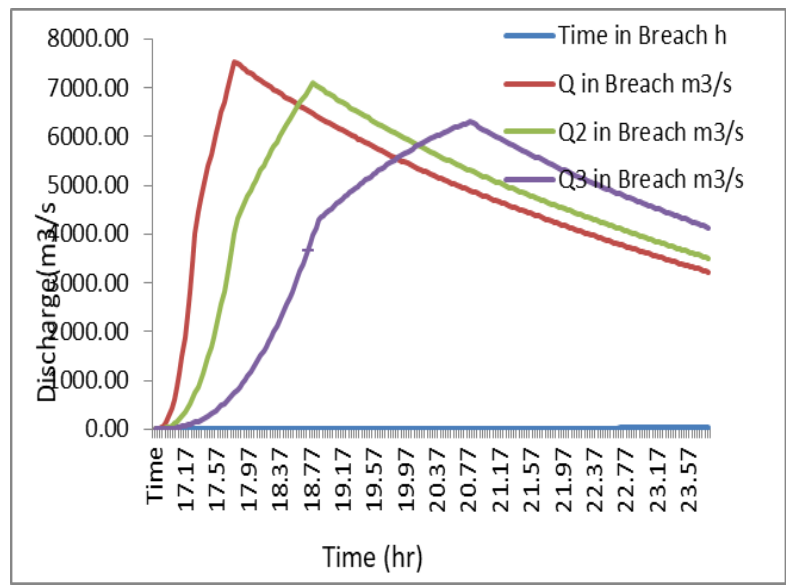

Fig 6 Flood Hydrographs for Different Breach Time

An increase in breach width leads to faster discharge of water through the breach. This means that the peak of the outflow hydrograph is sharp with small time base. It is observed that for an increase in breach width to $150 \mathrm{~m}$, the outflow is $8752.6 \mathrm{~m}^{3} / \mathrm{s}$ similarly, for $200 \mathrm{~m}$ the outflow is $10354 \mathrm{~m}^{3} / \mathrm{s}$. Variation in peak discharge vrs breach width is shown in Fig 7. 
Proc. of Eighth International Conference On Advances in Civil, Structural and Mechanical Engineering - ACSM 2018 Copyright (C) Institute of Research Engineers and Doctors, USA. All rights reserved.

ISBN: 978-1-63248-154-2 doi: 10.15224/978-1-63248-154-2-08

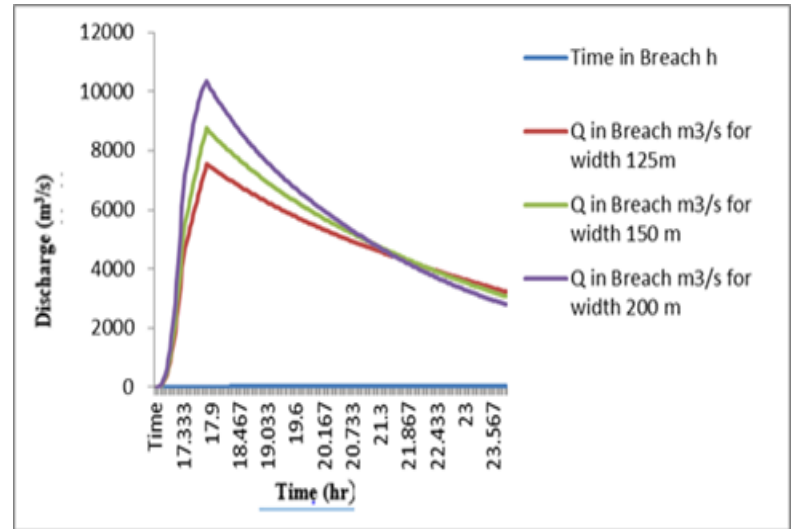

Fig 7 Flood Hydrographs for different Breach Width

Increase in inflow may be due to severe weather condition like cloud burst. With increase in the inflow, the reservoir fills earlier. This results in early breach initiation. There is also an increase in the peak of outflow hydrograph. The variation in peak discharge with respect to breach inflow (PMF) is shown in Fig 8.

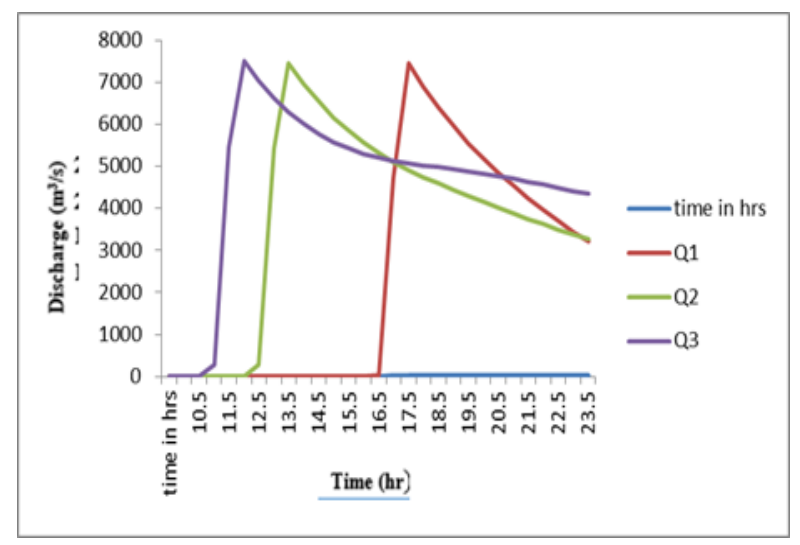

Fig 8 Flood Hydrographs for Different Inflow

In the initial model, a breach time of $1 \mathrm{hr}$, breach width of $125 \mathrm{~m}$ and design flood of $7536 \mathrm{~m}^{3} / \mathrm{s}$ is assumed for the purpose of analysis. For sensitivity analysis the inflow is increased in stages from $7625 \mathrm{~m}^{3} / \mathrm{s}$ to $7662.8 \mathrm{~m}^{3} / \mathrm{s}$. It is found that the maximum water level as well as the peak of the flood hydrograph at different stations increased with the increase in inflow into the reservoir. For a constant value of breach time and breach width, it is observed that the increase in the inflow into the reservoir had a negligible effect on maximum water level and a small effect on peak discharge.

When the Manning's Roughness Coefficient $(n)$ increases loss of energy will be there, which affect the wave speed. This loss of energy is dissipated through the boundary walls of the channel or the water surface.

Chow (1959) had been suggested us the value of Manning's $n$ in the range of $0.03-0.05$ for the regions in the bed gravels, cobbles and few boulders at the bottom with no vegetation in channel. As expected the velocities reduce with increase in Manning's n, and vice versa. This affects the maximum discharge as can be seen in Fig 9.

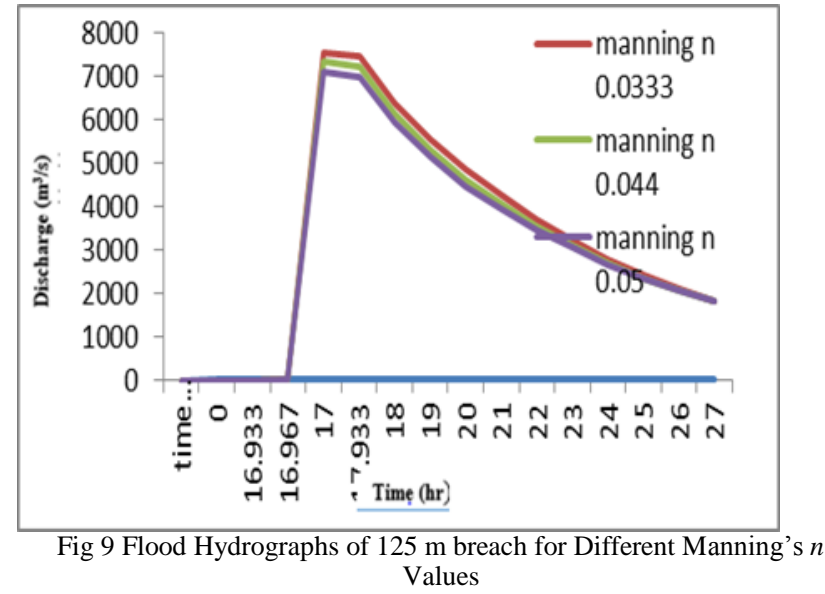

\section{Flood Map}

MIKE 11 is integrated with GIS for automated model development and flood mapping. The automated and integrated GIS process provides a very efficient modeling environment that allows the engineer to establish a wellorganized production line. Flood mapping provides highly visual presentations of flood plain inundation and can be overlaid with other GIS data such as topography, roads and others. This information is thus readily available to flood managers, concerned organizations and the general public, for both planning purposes and in emergency situations. Flood maps and video animations are key results of dam break studies, illustrating the floods simulated for the different failure modes, hydraulic conditions etc., in combination with other GIS information on infrastructure, location of emergency services, etc. Generating flood maps basically requires two set of input: a DEM and MIKE 11 simulation results. The information is combined into a flood map as shown in Fig 10. It describes the flood map at different breach width.

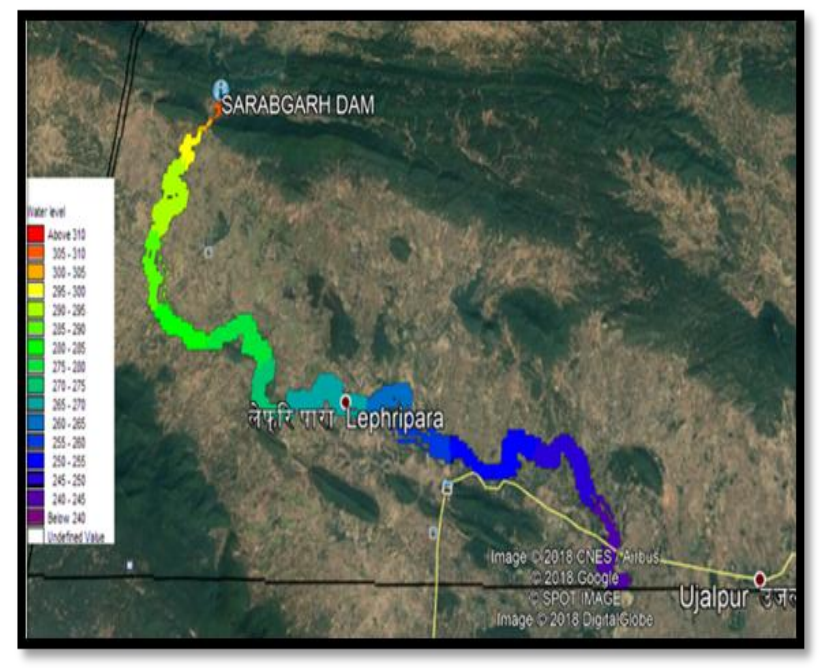

Fig 10 Flood Map

From Fig 10, it can be clearly observed that the water elevation just below the dam is more than 310 meter. The water elevation is varying from 310 meter to 245 meter from dam site to downstream side of the river reach over a distance of 27.7 kilometers.

\section{Emergency Action Plan (EAP)}


Proc. of Eighth International Conference On Advances in Civil, Structural and Mechanical Engineering - ACSM 2018 Copyright (C) Institute of Research Engineers and Doctors, USA. All rights reserved.

ISBN: 978-1-63248-154-2 doi: 10.15224/978-1-63248-154-2-08

The first step is detection of an event that is unusual or has a potential of raising an emergency alarm which can be observed near or at the dam site. For this study, a severe weather condition with heavy rainfall is considered the first step of event detection. It has been observed that breaching of the dam starts when the reservoir level at $310 \mathrm{~m}$ that is more than the top bank level of the reservoir. Breaching started at $16.9 \mathrm{hrs}$ but peak discharge occurred at17.9 hrs. An Emergency Level-3 is a situation for a dam failure is defined by flow occurring over the embankment causing damage to the embankment slope and reservoir level exceeding the top of the dam with probability of continuation. The variation of water level with respect to distance and the emergency signal with respect to the area that will be highly affected are shown in Table -1 .

TABLE I Emergency Level Indication

\begin{tabular}{|c|c|c|c|c|}
\hline $\begin{array}{l}\text { Chainage } \\
\text { point }\end{array}$ & $\begin{array}{l}\text { Distance } \\
\text { (meters) }\end{array}$ & $\begin{array}{l}\text { Maximum } \\
\text { water } \\
\text { level(m) }\end{array}$ & $\begin{array}{c}\text { Time taken } \\
\text { from breach } \\
(\mathrm{hr})\end{array}$ & $\begin{array}{l}\text { Signal and } \\
\text { danger level }\end{array}$ \\
\hline 1 & 1000 & 310.6247 & $1: 04: 1.2$ & yellow \\
\hline 2 & 2000 & 306.9295 & 1:08:0.2 & yellow \\
\hline 3 & 3000 & 297.1577 & 1:101.2: & orange \\
\hline 4 & 4000 & 295.7886 & $1: 18: 1.2$ & Orange \\
\hline 5 & 5000 & 293.7064 & $1: 22: 0.2$ & Orange \\
\hline 6 & 6000 & 292.0653 & $1: 27: 1.2$ & Orange \\
\hline 7 & 7000 & 289.9334 & $1: 28: 0.2$ & Orange \\
\hline 8 & 8000 & 286.9458 & $1: 30: 0.2$ & Orange \\
\hline 9 & 9000 & 285.1414 & $1: 34: 0.2$ & Orange \\
\hline 10 & 10000 & 282.5076 & $1: 38: 1.2$ & orange \\
\hline 11 & 11000 & 278.9545 & $1: 40: 0.2$ & orange \\
\hline 12 & 12000 & 276.9636 & $1: 46: 1.2$ & red \\
\hline 13 & 13000 & 275.7436 & $1: 48: 1.2$ & red \\
\hline 14 & 14000 & 273.0526 & $1: 50: 0.2$ & red \\
\hline 15 & 15000 & 269.3537 & $1: 56: 1.2$ & red \\
\hline 16 & 16000 & 268.6953 & 1:58:0.2 & red \\
\hline 17 & 17000 & 266.8194 & $2: 04: 0.2$ & red \\
\hline 18 & 18000 & 264.1608 & $2: 10: 1.2$ & red \\
\hline 19 & 19000 & 261.7494 & $2: 16: 0.2$ & red \\
\hline 20 & 20000 & 258.5186 & $2: 18: 0.2$ & orange \\
\hline 21 & 21000 & 255.6157 & $2: 20: 0.2$ & orange \\
\hline 22 & 22000 & 254.1997 & $2: 26: 0.2$ & orange \\
\hline 23 & 23000 & 252.1852 & $2: 32: 1.2$ & orange \\
\hline 24 & 24000 & 250.5306 & $2: 38: 1.2$ & orange \\
\hline 25 & 25000 & 248.9454 & $2: 40: 1.2$ & orange \\
\hline 26 & 26000 & 246.9153 & $2: 48: 1.2$ & orange \\
\hline 27 & 27000 & 244.1868 & $2: 54: 0.2$ & orange \\
\hline 28 & 27700 & 242.6530 & $2: 58: 1.2$ & orange \\
\hline
\end{tabular}

As the flow is occurring over the embankment and reservoir water level is expected to increase because the peak discharge has not passed, it signifies Emergency Level-3. At this stage, the dam owner should first of all take up the emergency helpline and then contact the engineers of the Water Resource Department (WRD). The Emergency Management group should give warnings and evacuate the residents at risk in the downstream region. The owner should give regular updates to the Water Resource Department for assistance and instructions. People monitoring the failing structure should maintain a safe distance to avoid injuries and risk. After the completion of all the necessary tasks, the EAP operation is terminated eventually completing the follow up procedures.

\section{CONCLUSIONS}

From the dam breach analysis using MIKE 11, carried out for Sarabgarh Irrigation Project in India, the following conclusions have been drawn:

1) Breaching starts at $16.9 \mathrm{hrs}$. From the time when reservoir starts filling and peak discharge of $7536 \mathrm{~m}^{3} / \mathrm{s}$ is obtained at $17.93 \mathrm{hrs}$ which means the dam fails in $1 \mathrm{hrs}$ after impeaching of the flood at the dam.

2) Peak discharge through the breach reduces by $5.9 \%$

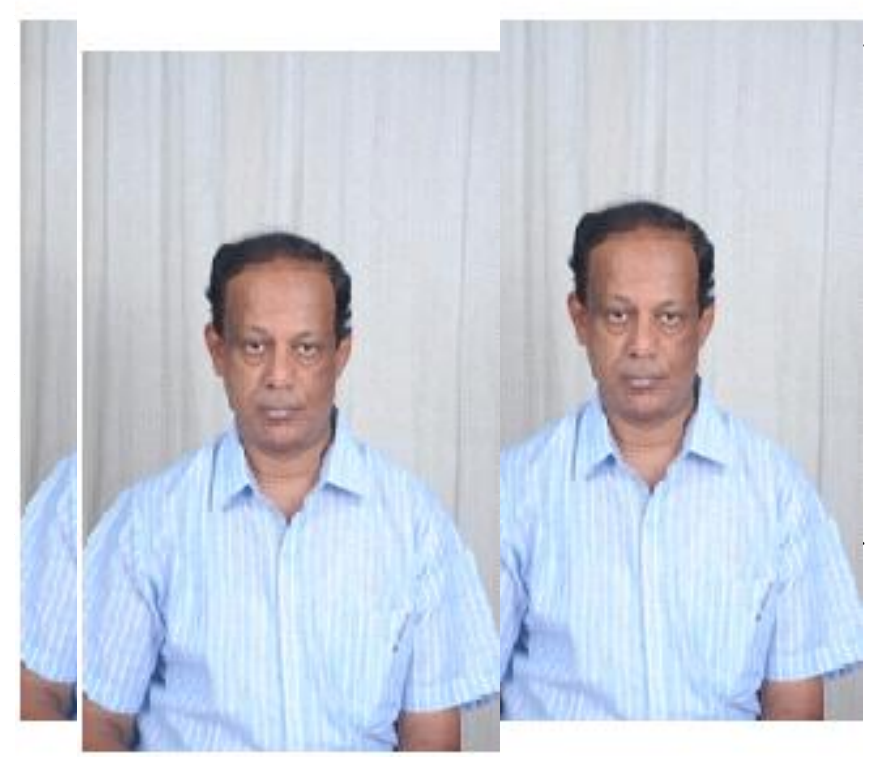

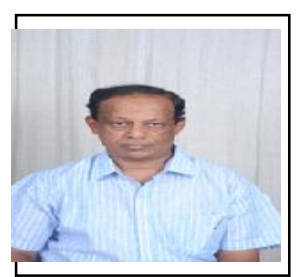

Patra K.C

Professor of Civil Engineering Department National Institute of Technology Rourkela Rourkela, 769008, India 